\title{
Effect of inhibition of oxygen free radical on ovulation and progesterone production by the in-vitro perfused rabbit ovary*
}

\author{
T. Miyazaki, K. Sueoka, A. M. Dharmarajan, S. J. Atlas, G. B. Bulkley and \\ E. E. Wallach
}

The Johns Hopkins University School of Medicine, Departments of Gynecology and Obstetrics and Surgery, Baltimore, Maryland 21205, USA

\begin{abstract}
Summary. The potential role of oxygen free radicals in hCG-induced ovulation was investigated using the free radical scavenging enzymes superoxide dismutase (SOD) and/or catalase with the in-vitro perfused rabbit ovary preparation. SOD $(25 \mu \mathrm{g} / \mathrm{ml})$ and SOD + catalase $(25 \mu \mathrm{g} / \mathrm{ml})$ significantly reduced the $\%$ of large follicles that ovulated during perfusion $(P<0.005)$. Neither maturity nor degeneration of ovulated ova and follicular oocytes was affected by SOD and/or catalase. Progesterone concentration in the perfusate was significantly increased in the SOD + catalase treatment group $(P<0.01)$. These results indicate a significant role for oxygen free radicals in the process of ovulation.
\end{abstract}

Keywords: free radicals; ovulation; progesterone; superoxide dismutase

\section{Introduction}

The mechanism of ovulation has been compared to an inflammatory reaction (Espey, 1980). Components of inflammation that are also found in the process of ovulation include synthesis and release of prostaglandins (Armstrong, 1981), the action of proteolytic enzymes (Strickland \& Beers, 1976; Yoshimura et al., 1987a), and appearance of other mediators such as bradykinin (Yoshimura $e t$ al., 1988) and histamine (Kitai et al., 1985). Increased vascular permeability and apical thrombosis are visible in the follicular capillaries of rabbits induced to ovulate with hCG (Kanzaki et al., 1982).

Toxic metabolites of oxygen, including the superoxide anion radical $\left(\mathrm{O}_{2}{ }^{-}\right)$, hydrogen peroxide $\left(\mathrm{H}_{2} \mathrm{O}_{2}\right)$, and the hydroxyl radical $(\mathrm{OH} \cdot)$, are important mediators of inflammatory tissue injury (McCord, 1974; Del Maestro et al., 1980; Weiss, 1986) (Fig. 1). Moreover, these highly toxic oxygen metabolites have been found to be the final common mediator of tissue damage in a large number of disparate processes, including inflammation and post-ischaemic re-perfusion injury (Bulkley, 1983; Weiss, 1986; Bulkley, 1987). There are therefore striking similarities between many known actions of oxygen-derived free radicals and the events leading to follicle rupture.

Because of their highly reactive nature, free radicals have extremely short half-lives (often measured in nanoseconds) and consequently do not accumulate in tissues at levels that can be readily detected. Many investigators have therefore used indirect means, at least in initial studies, to characterize free radical mechanisms in physiological processes (Bulkley, 1987). An indirect approach frequently employed is the use of the highly specific inhibitor of free radicals, superoxide dismutase (SOD: EC 1.15.1.1).

Ovulation can be consistently induced by administration of hCG in an isolated in-vitro perfused rabbit ovary system (Kobayashi et al., 1981). This in-vitro system offers certain advantages for the

\footnotetext{
*Reprint requests to: Dr E. E. Wallach.
} 
investigation of the effects of scavenging enzymes such as SOD, for their half-life is less than $10 \mathrm{~min}$ in vivo due to renal excretion. The objective of this study was to use the in-vitro perfusion system to determine whether the inhibition of toxic oxygen metabolites with SOD, catalase (an enzyme catalysing the breakdown of $\mathrm{H}_{2} \mathrm{O}_{2}$ ), or both would affect hCG-induced follicle rupture, oocyte maturation, and progesterone production.

\section{Materials and Methods}

Animals. Sexually mature New Zealand White female rabbits were isolated for a minimum of 3 weeks before the experimental procedure. The rabbits were caged individually under controlled light and temperature conditions and given free access to Purina Rabbit chow (Ralston-Purina, St Louis, MO, USA) and water.

In-vitro perfusion. Rabbits weighing at least $3.5 \mathrm{~kg}$ were anaesthetized with intravenous pentobarbitone sodium $(32 \mathrm{mg} / \mathrm{kg})$, given heparin sulphate $(120 \mathrm{units} / \mathrm{kg})$ for anticoagulation and then subjected to laparotomy. Ovaries were excluded from study if they appeared immature or if $50 \%$ or more of the surface follicles appeared haemorrhagic. Each ovarian artery was cannulated in situ, and the ovary with its ovarian artery and vein and supportive adipose tissue was removed and perfused in vitro with $150 \mathrm{ml}$ of tissue culture Medium 199 (M. A. Bioproducts, Walkerville, MD, USA) supplemented with insulin $(20 \mathrm{U} / \mathrm{l})$, heparin sulphate $(200 \mathrm{U} / \mathrm{l})$, streptomycin $(50 \mathrm{mg} / \mathrm{l})$, and pencillin $\mathrm{G}$ $(75 \mathrm{mg} / \mathrm{ml})$. The cannulation procedure and perfusion apparatus have been previously described in detail (Lambertsen et al., 1976; Kobayashi et al., 1981). A capillary membrane oxygenator gassed with a mixture of $95 \% \mathrm{O}_{2}$ and $5 \% \mathrm{CO}_{2}$ was used to oxygenate the medium. One ovary of each animal was perfused with medium containing highly purified, pharmaceutical grade bovine erythrocyte SOD (kindly supplied by Dr Leopold Flohe, Grunenthal, GmbH, Aachen, FRG) at $25 \mu \mathrm{g} / \mathrm{ml}$ and/or bovine liver catalase (Worthington Biochemical, Freehold, NJ, USA) at $25 \mu \mathrm{g} / \mathrm{ml}$, while the contralateral ovary was perfused in a separate chamber with medium alone and thereby served as a control. The enzyme doses were chosen because they had been successfully used previously in other systems (Kuehl et al., 1979; Smolen \& Weissmann, 1980) and we found them to be the lowest effective doses (data not shown). Four ovaries were perfused at one time. The left ovary of the first rabbit received treatment and the right ovary was the control. The order was reversed for the second rabbit. At $30 \mathrm{~min}$ after the onset the perfusion, both ovaries were stimulated by addition of 50 i.u. hCG (Organon Inc., West Orange, NJ, USA) to induce ovulation, and perfusion was continued for $12 \mathrm{~h}$ thereafter.

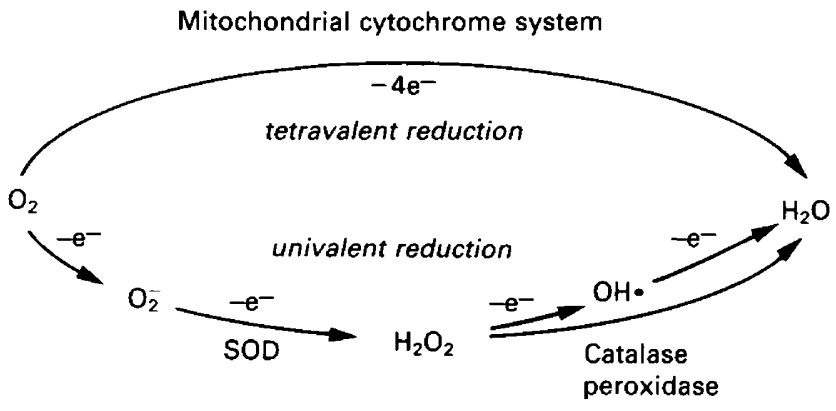

Fig. 1. Actions of oxygen free radicals within the cell. Diagram of $1-5 \%$ of oxygen that is metabolized by the cell is reduced univalently, producing the toxic oxygen metabolites, the superoxide and hydroxyl free radicals and hydrogen peroxide. A number of intracellular enzyme systems have evolved to deal with these toxic species, including the superoxide dismutases (SOD), the catalases and the peroxidases, as well as glutathione and other scavenging systems.

Ovaries were observed every $15 \mathrm{~min}$ for evidence of follicle growth and rupture. A follicle was considered to be ruptured when the cumulus containing an ovum was observed protruding from the ovarian surface. Ovulation time, the elapsed time between addition of hCG and follicle rupture, was recorded. The ovulated ovum, surrounded by its cumulus mass, was carefully recovered from the ovarian surface. Follicular oocytes were recovered from mature, but unruptured follicles ( $\geq 1.5 \mathrm{~mm}$ in diameter) after perfusion. Both ovulated ova and follicular oocytes were assessed for stage of maturity and signs of degeneration, as previously described (Kobayashi et al., 1981). The degree of ovum maturity was expressed as the percentage of oocytes which had achieved germinal vesicle breakdown (GVBD). Ovulatory efficiency, defined as the total number of ova released divided by the total number of large follicles $(\geq 1.5 \mathrm{~mm})$, was calculated for each group. In a random group of rabbits, the number of preovulatory follicles per ovary that may potentially ovulate vary before treatment. During the $12 \mathrm{~h}$ of perfusion, perfusate samples $(2 \mathrm{ml})$ were 
withdrawn from the perfusion chamber at $0,1,2,4,6,8,10$ and $12 \mathrm{~h}$ after hCG administration and replaced with an equal volume of fresh medium. The samples were frozen and stored at $-20^{\circ} \mathrm{C}$ for later measurement of progesterone. Three experimental groups were defined and 4 rabbits were used in each group.

Progesterone radioimmunoassays. Progesterone concentration in the perfusate was measured using a solid-phase kit (Diagnostic Products Co., Los Angeles, CA, USA) (Yoshimura et al., 1987b) in which the progesterone antibody is bound covalently to the inner surface of polypropylene assay tubes. All samples and progesterone standards $(100 \mu \mathrm{l})$ were assayed in duplicate. The sensitivity was $0.05 \mathrm{ng} / \mathrm{ml}$, and the intra- and inter-assay variations were $7.5 \%$ and $6.6 \%$, respectively.

Statistical analysis. ANOVA, followed by the Student-Newman-Keuls test, was used to analyse ovulation time and a $2 \times 4$ contingency table was used to analyse ovulatory efficiency. Progesterone data were evaluated by ANOVA with repeated measures. A probability of $<0.05$ was considered to be significant.

\section{Results}

\section{Effect of SOD and/or catalase on hCG-induced ovulation}

The ovulatory efficiency was significantly reduced by SOD and SOD + catalase compared with the control groups. Ovulatory efficiency fell from 82 to $30 \%(P<0.005)$ with SOD treatment and from 96 to $29 \%(P<0.001)$ with SOD + catalase treatment, but there was no significant difference between the two treatments. In addition, the mean ovulation time was significantly prolonged in the SOD + catalase-treated group $(P<0.005)$ (Table 1). Catalase alone did not significantly affect ovulation.

Table 1. Characteristics of rabbit ovaries perfused with SOD and/or catalase

\begin{tabular}{lcccc}
\hline & SOD & Catalase & SOD + catalase & Control \\
\hline No. of ovaries perfused & 4 & 4 & 4 & 12 \\
No. of ovaries ovulating & 2 & 4 & 4 & 12 \\
Total no. of follicles & 20 & 15 & 31 & 63 \\
Total no. of ovulations & 6 & 10 & 9 & 54 \\
Ovulation time (h) $\dagger$ & $6.78 \pm 0.98$ & $6.80 \pm 0.86$ & $9.13 \pm 0.93^{*}$ & $5.92 \pm 0.37$ \\
\hline
\end{tabular}

Values are mean \pm s.e.m.

$\dagger$ Time from addition of hCG to follicle rupture for those follicles that ruptured.

${ }^{*} P<0.005$ compared with control.

No significant difference was noted in percentage of ovulated ova or follicular oocytes achieving GVBD and degeneration in any of the groups examined (Table 2).

Table 2. Stage of maturity and degeneration of ovulated ova and follicular oocytes

\begin{tabular}{lcccc}
\hline & SOD & Catalase & SOD + Catalase & Control \\
\hline Ovulated ova & & & & \\
$\quad$ Total no. & 6 & 10 & 9 & 54 \\
\% GVDB & 100 & $90 \cdot 0$ & $88 \cdot 9$ & $88 \cdot 9$ \\
\% Degeneration & $16 \cdot 7$ & $10 \cdot 0$ & $33 \cdot 3$ & $20 \cdot 4$ \\
Follicular oocytes & & & & \\
Total no. & 14 & 5 & 22 & 9 \\
\% GVDB & 100 & 100 & 100 & 100 \\
\% Degeneration & $21 \cdot 4$ & 0 & $9 \cdot 1$ & $33 \cdot 3$ \\
\hline
\end{tabular}




\section{Progesterone concentrations}

Progesterone production by the control ovary of each experimental group reached its maximum at $4 \mathrm{~h}$ after hCG administration. Progesterone production in the SOD + catalase treated group was significantly increased $(P<0.01)$ compared to the contralateral control. This increase was evident by $2 \mathrm{~h}$ after hCG administration (Fig. 2). The concentration of progesterone in the perfusate of ovaries treated with SOD alone and catalase alone increased in a similar manner, and was not different from respective controls.

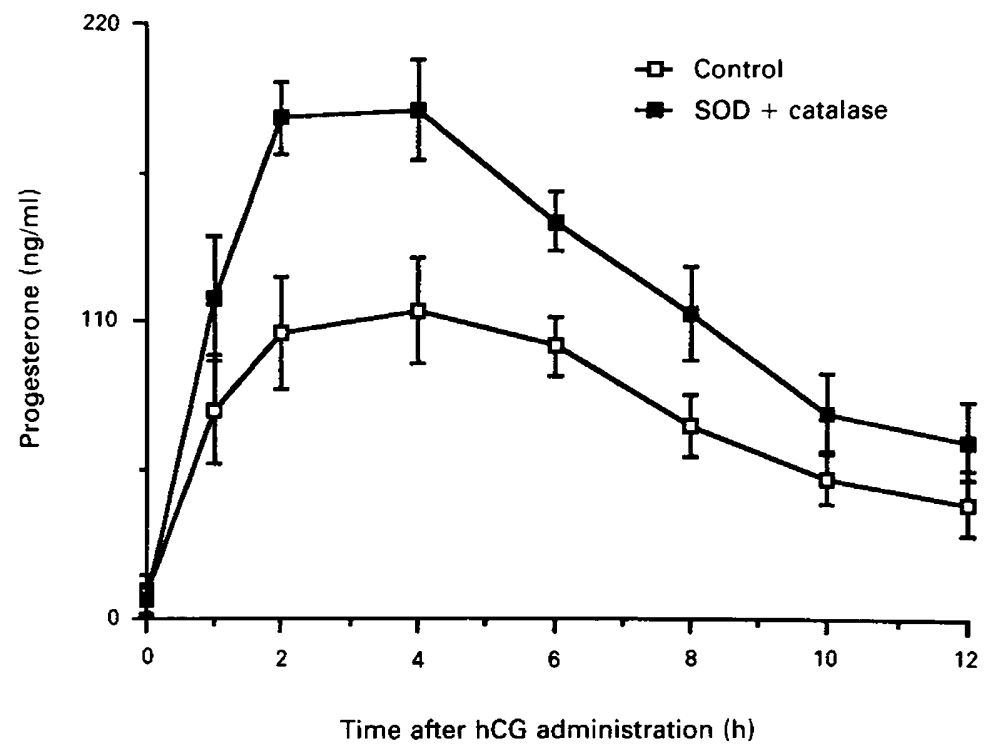

Fig. 2. Concentrations of progesterone in the perfusate of ovaries treated with SOD + catalase and the contralateral controls. Data points are the mean \pm s.e. of 4 perfused ovaries from at least 2 different experiments. Progesterone was significantly $(P<0.01)$ increased by treatment, as measured by ANOVA with repeated measures.

\section{Discussion}

Many factors may result in the formation of toxic metabolites of oxygen in tissues. These include mitochondrial, endoplasmic reticular and nuclear membrane electron transport systems, oxidant enzymes such as cytochrome $\mathbf{P}_{450}$, xanthine oxidase, and lipoxygenase, and the NAD(P)H oxidase of phagocytic cells (Weiss, 1986; Cross et al., 1987) (Fig. 1). Although these experiments were not designed to identify the precise source of radical generation, the fact that SOD blocked ovulation in an asanguineous (medium-perfused) preparation argues against that source being circulating neutrophils, a common biological source of radical generation. Regardless of the source, the scavenging of $\mathrm{O}_{2}{ }^{-}$with SOD significantly inhibited follicle rupture in these perfused rabbit ovaries, while the removal of $\mathrm{H}_{2} \mathrm{O}_{2}$ with catalase had no apparent effect. These findings suggest that $\mathrm{O}_{2}{ }^{-}$, or a secondary radical species dependent for its production on $\mathrm{O}_{2}{ }^{-}$generation, plays an essential role in follicle rupture. In these experiments we have used SOD to determine that the process of ovulation was dependent upon the activity of $\mathrm{O}_{2}{ }^{-}$. Although these approaches have been used commonly in the past by others in the field of free radical biology (Bulkley, 1987), they offer only indirect evidence for $\mathrm{O}_{2}{ }^{-}$generation. SOD is a very specific enzyme; in the 20 years since its description by McCord \& Fridovich (1969), no other biological action of this compound has been 


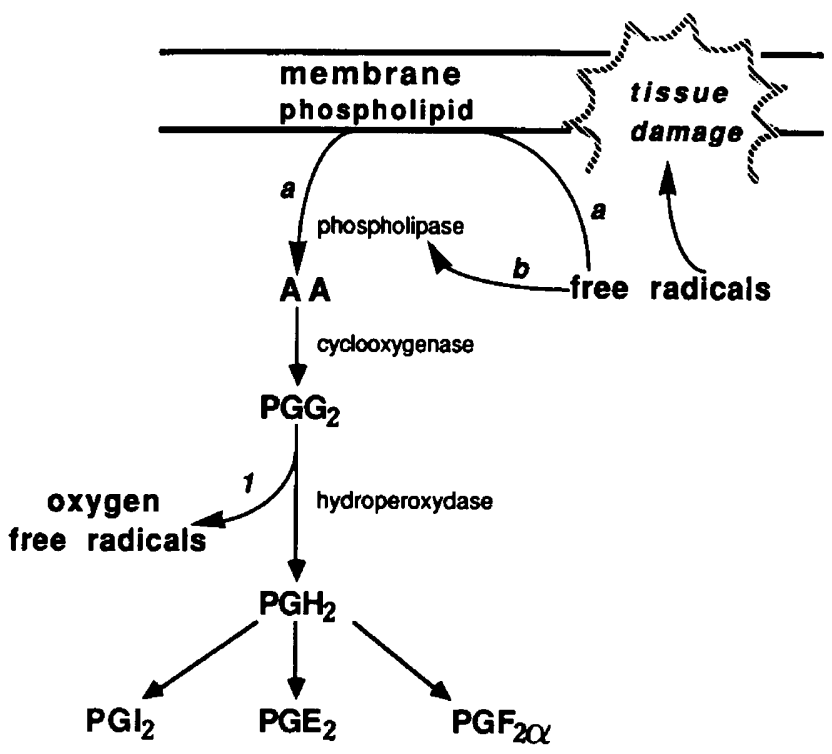

Fig. 3. Scheme for free radical interactions with prostaglandins. Free radicals are produced during reduction of PGG-2 to PGH-2 (1). They may also increase PG production by (a) directly releasing arachidonic acid (AA) from membranes, and/or (b) activating phospholipase.

demonstrated (Bulkley, 1987). It is therefore unlikely that non-specific effects of the highly purified enzymes used in these experiments could account for our observations, but the possibility cannot be disproved without the use of inactivated enzymes.

Our observations do not indicate a role for $\mathrm{H}_{2} \mathrm{O}_{2}$ in ovulation, although the presence of both SOD and catalase prolonged the ovulation time of those follicles that ovulated. While these data appear to suggest a more important role of $\mathrm{O}_{2}{ }^{-}$than $\mathrm{H}_{2} \mathrm{O}_{2}$ in follicle rupture, $\mathrm{H}_{2} \mathrm{O}_{2}$ has been found to inactivate SOD slowly and irreversibly (Hodgson \& Fridovich, 1975). The addition of catalase may have protected SOD from inactivation by $\mathrm{H}_{2} \mathrm{O}_{2}$.

In this study, SOD and/or catalase did not alter the percentage of ovulated ova or follicular oocytes undergoing GVBD or degeneration. These data suggest that oxygen free radicals may not play a role in the processes of oocyte maturation or degeneration.

Progesterone concentration significantly increased in those ovaries treated with SOD + catalase. The reason for this increase is not clear, but SOD + catalase might protect steroid-producing cells from damage due to the secondary generation of $\mathrm{OH} \cdot$ from $\mathrm{O}_{2}{ }^{-}+\mathrm{H}_{2} \mathrm{O}_{2}$. Alternatively, treatment may have shifted steroid metabolism, for instance changing the ratio between progesterone and 20a-dihydroprogesterone, or altered hormone secretion.

The interaction between oxygen free radicals and PGs, both of which are intimately involved in the inflammatory process, is complex. Oxygen free radicals are not only formed during PG biosynthesis, but may themselves initiate the arachidonic acid cascade (Fig. 3), many of the steps of which are radical-dependent lipid peroxidations. Oxygen free radicals may cause follicle rupture by activating phospholipase (Baud et al., 1981) and by stimulating direct release of arachidonic acid from biomembranes (Seeger et al., 1982) (Fig. 3). Furthermore, it has been found that SOD decreases PG production (Baud et al., 1981) and inhibits cyclooxygenase and phospholipase activity (Rahimtula \& O'Brien, 1976; O'Brien \& Hulett, 1980; Parente, 1982). Free radicals may affect follicle rupture through prostaglandins, by releasing proteolytic enzymes from lysosomes, and/or by direct attack on the follicle wall.

In conclusion, the data derived using an in-vitro perfusion model clearly demonstrated that the oxygen free radical, superoxide, plays a role in the mechanical process of ovulation. Future studies 
will be needed, however, to clarify further the precise role of each particular radical species in the process.

We thank Mr Ramesh Ghodogaonkar and Ms Beverly Smith for excellent technical assistance; and Ms Fran Karas for help with preparation of the manuscript. Supported by HD-19430, DK31764, Population Center Grant HD 06268, a SmithKline Beckman Fellowship (T.M.), and the Lalor and the Lillian and Mitchell Duberstein Foundations.

\section{References}

Armstrong, D.T. (1981) Prostaglandin and follicular function. J. Reprod. Fert. 62, 283-291.

Baud, L., Nivetz, M-P., Chansel, D. \& Ardaillou, $R$. (1981) Stimulation by oxygen radicals of prostaglandin production by rat renal glomeruli. Kidney Int. 20, $332-339$.

Bulkley, G.B. (1983) The role of oxygen free radicals in human disease processes. Surgery 94, 407-411.

Bulkley, G.B. (1987) Free radical-mediated reperfusion injury: a selective review. Br. J. Cancer (Suppl.) 55, 66-73.

Cross, C.E., Halliwell, B., Borish, E.T., et al. (1987) Oxygen radicals and human disease. Ann. Intern. Med. 107, 526-545.

Del Maestro, R.F., Thaw, H.H., Bjork, J., Planker, M. \& Arfors, K-E. (1980) Free radicals as mediators of tissue injury. Acta physiol. scand. (Suppl.) 492, 43-57.

Espey, L.L. (1980) Ovulation as an inflammatory reaction -a hypothesis. Biol. Reprod. 22, 73-106.

Hodgson, E.K. \& Fridovich, I. (1975) The interaction of bovine erythrocyte superoxide dismutase with hydrogen peroxide: inactivation of the enzyme. Biochemistry, NY 14, 5294-5299.

Kanzaki, H., Okamura, H., Okuda, Y., Takenaka, A., Morimoto, K. \& Nishimura, T. (1982) Scanning electron microscopic study of rabbit ovarian follicle microvasculature using resin injection-corrosion casts. J. Anat. 134, 697-704.

Kitai, H., Kobayashi, Y., Santulli, R., Wright, K.H. \& Wallach, E.E. (1985) The relationship between prostaglandins and histamine in the ovulatory process as determined with the in vitro perfused rabbit ovary. Fert. Steril. 43, 646-651.

Kobayashi Y., Wright K.H., Santulli R. \& Wallach E.E. (1981) Ovulation and ovum maturation in the rabbit ovary perfused in vitro. Biol. Reprod. 24, 483-490.

Kuehl, F.A., Jr, Humes, J.L., Torchiana, M.L., Ham, E.A. \& Egan, R.W. (1979) Oxygen-centered radicals in inflammatory processes. In: Advances in Inflammation Research, pp. 419-430. Eds G. Weissman, B. Samuelsson \& R. Paoletti. Raven Press, New York.

Lambertsen, C.J., Jr., Greenbaum, D.F., Wright, K.H. \& Wallach, E.E. (1976) In vitro studies of ovulation in the perfused rabbit ovary. Fert. Steril. 27, 178-187.

McCord, J.M. (1974) Free radicals and inflammation: protection of synovial fluid by superoxide dismutase. Science, $N Y 185,525-531$.
McCord, J.M. \& Fridovich, I. (1969) Superoxide dismutase. J. biol. Chem. 24, 6049-6055.

O'Brien, P.J. \& Hulett, L.G. (1980) Hydroxyl radical involvement in the luminol chemiluminescence from the reaction of arachidonic acid with sheep vesicular gland microsomes. Prostaglandins 19, 683-691.

Parente, L. (1982) Study on the effect of superoxide dismutase on arachidonic acid metabolism. Prostaglandins 23, 725-730.

Rahimtula, A. \& O'Brien, P.J. (1976) The possible involvement of singlet oxygen in prostaglandin biosynthesis. Biochem. Biophys. Res. Commun. 70, 893-899.

Seeger, W., Wolf, H., Stahler, G., Neuhof, H. \& Roka, L. (1982) Influence of tocopherol, its chromane compound, phytyl chains and superoxide dismutase on increased vascular resistance and permeability due to arachidonate metabolism in isolated rabbit lung. Prostaglandins 23, 175-184.

Smolen, J.E. \& Weissmann, G. (1980) Effects of indomethacin, 5,8,11,14-eicosatetraynoic acid, and $p$ bromophenacyl bromide on lysosomal enzyme release and superoxide anion generation by human polymorphonuclear leukocytes. Biochem. Pharmacol. 29, 533-538.

Strickland, S. \& Beers, W.H. (1976) Studies on the role of plasminogen activator in ovulation. J. biol. Chem. 251, 5694-5702.

Weiss, S.J. (1986) Oxygen, ischemia and inflammation. Acta physiol. scand. (Suppl.) 548, 9-37.

Yoshimura, Y., Santulli, R., Atlas, S.J., Fujii, S. \& Wallach, E.E. (1987a) The effects of proteolytic enzymes on in vitro ovulation in the rabbit. $A m . J$. Obstet. Gynecol. 157, 468-475.

Yoshimura, Y., Hosoi, Y., Bongiovanni, A.M., Santulli, R., Atlas, S.J. \& Wallach, E.E. (1987b) Are ovarian steroids required for ovum maturation and fertilization? Effects of cyanoketone on the in vitro perfused rabbit ovary. Endocrinology 120, 2555-2561.

Yoshimura, Y., Espey, L., Hosoi, Y., Adachi, T., Atlas, S.J., Ghodgaonkar, R.B., Dubin, N.H. \& Wallach, E.E. (1988) The effects of bradykinin on ovulation and prostaglandin production by the perfused rabbit ovary. Endocrinology 122, 2540-2546.

Received 26 April 1990 